\title{
Treatment of acute gonococcal urethritis in men with simultaneous infection with Chlamydia trachomatis
}

\author{
PÉTER A CSÁNGÓ,* AUd SALVESON,† THOR GUNDERSEN, \\ GARLETTA JAGARS,* AND ODD BJERK†
}

From the *Department of Microbiology, Vest-Agder Central Hospital, 4600 Kristiansand S, †Department of Clinical Research, Hoffmann-La Roche \& Co, Oslo, and ¥Division of Dermatovenereology, City Health Department, Oslo, Norway

SUMMARY Each of 201 men with symptoms and signs of acute urethritis was randomly assigned to one of two treatment regimens: ampicillin $(2 \mathrm{~g})$ plus probenecid $(1 \mathrm{~g})$, or sulphamethoxazoletrimethoprim (SMX-TMP) (sulphamethoxazole $1600 \mathrm{mg}$ plus trimethoprim $320 \mathrm{mg}$ ) four tablets twice daily for two days. Before treatment Neisseria gonorrhoeae was isolated from 162 patients, while coexistent Chlamydia trachomatis was recovered from $42(26 \%)$ men. After treatment $N$ gonorrhoeae persisted in $11(14 \cdot 3 \%)$ of the 77 patients treated with ampicillin and probenecid and in three $(3.5 \%)$ of the 85 treated with SMX-TMP $(\mathrm{p}<0.05)$, while $C$ trachomatis persisted in four $(16 \%)$ of the 25 men treated with SMX-TMP and in all 17 patients treated with ampicillin and probenecid.

SMX-TMP was thus more effective than ampicillin in treating acute gonorrhoea in men and in eradicating concurrent $C$ trachomatis infection.

\section{Introduction}

Chlamydia trachomatis is a common sexually transmitted organism causing non-gonococcal urethritis, salpingitis, and inclusion conjunctivitis, and its association with other conditions such as endometritis, epididymitis, and Reiter's disease has been documented. ${ }^{1-3} C$ trachomatis commonly occurs in men with gonorrhoea and can be isolated from about one in four men with gonococcal urethritis. ${ }^{1-4}$ Concurrent infection with Neisseria gonorrhoeae is the major cause of postgonococcal urethritis. ${ }^{1-5}$

A high percentage of men with double infection are likely to develop postgonococcal urethritis after treatment for gonorrhoea with penicillin derivatives or spectinomycin.1-5 The treatment of acute gonococcal urethritis with sulphamethoxazole-trimethoprim (SMX-TMP) is well documented, ${ }^{6-13}$ and one regimen is four tablets by mouth twice daily for two days. This regimen is particularly effective and suitable because it is relatively short term, gives high cure rates, is a possible alternative against

Address for reprints: Dr P A Csángó, Department of Microbiology, Vest-Agder Central Hospital, N-4600 Kristiansand S, Norway

Accepted for publication 6 October 1983 $\beta$-lactamase producing gonococci, does not mask concomitant syphilis, and may cure pharyngeal infection. ${ }^{6-12}$ The combination of sulphamethoxazole and trimethoprim was effective against $C$ trachomatis in vitro, ${ }^{14} 15$ and when used in clinical studies it was found to eradicate the organism and symptoms of urethritis in more than $90 \%$ of patients. ${ }^{12} 14$ Sattler and Ruskin stressed the need to undertake a study to test SMX-TMP in double infections with $N$ gonorrhoeae and $C$ trachomatis. ${ }^{10}$ In one such study a schedule of four doses of SMXTMP in two days was effective in eradicating gonococci and $C$ trachomatis in nine of 10 women with dual infection. ${ }^{12}$

Mahony et al found that the incidence of postgonococcal urethritis was significantly lower in patients with gonorrhoea treated with SMX-TMP than those treated with penicillin. ${ }^{7}$ In a study by Austin et al the incidence of postgonococcal urethritis following treatment with SMX-TMP was the same as after treatment of gonorrhoea with tetracycline. $^{8}$

Despite these favourable results, SMX-TMP has not previously been the subject of a controlled clinical trial of the treatment of double infections in acute urethritis in men. This investigation studied the 
efficacy of four doses of SMX-TMP in two days in eliminating both gonococci and $C$ trachomatis from the urethra of men with acute gonococcal urethritis.

\section{Patients, materials, and methods}

A total of 201 consecutive male patients with symptoms of acute urethritis of less than seven days' duration were enrolled in the study. Patients were included if there was a urethral discharge and if there were Gram negative diplococci in Gram stained smears of urethral exudate.

\section{MICROBIOLOGICAL METHODS}

Specimens were obtained for the culture of $N$ gonorrhoeae and $C$ trachomatis before and two to three weeks after treatment. Specimens for $N$ gonorrhoeae were taken with a charcoal impregnated cotton swab and transported to the laboratory in Stuart's medium. The isolation medium described by $\emptyset$ degaard $e t a^{17}$ was used. Suspected colonies were confirmed by sugar fermentation tests, coagglutination tests (Phadebact Gonococcus Test, Pharmacia Diagnostics, Uppsala, Sweden), or both. Specimens for culture of $\boldsymbol{C}$ trachomatis were collected and transported as described by Csángo ${ }^{18}$; the organism was cultured on McCoy cells treated with cycloheximide. ${ }^{19}$

\section{Assessment of postgonococcal urethritis}

Postgonococcal urethritis was diagnosed if there were at least five polymorphonuclear leucocytes per high power field ( $\times 100$ objective) in the urethral smear after treatment. The smear was collected by gentle curettage of the urethra of all patients studied.

\section{TREATMENT}

Patients were allocated at random to one of two treatment groups (A or B) and received treatment at the first visit as follows: group A: single dose oral treatment consisting of $2 \mathrm{~g}$ ampicillin (Doktacillin $500 \mathrm{mg}$, Astra) and $1 \mathrm{~g}$ probenecid (Probecid, Astra); group B: two day oral treatment with SMXTMP (Bactrim, Hoffmann-La Roche) four tablets twice daily each tablet containing $\mathbf{4 0 0} \mathrm{mg}$ sulphamethoxazole and $80 \mathrm{mg}$ trimethoprim. Patients were excluded from the study if there had been previous or suspected allergic reactions to penicillins, sulphonamides, or trimethoprim, or if they had been treated with antibiotics within the previous 10 days.

Patients with persistent gonococcal infection (at the second or third visit) were treated with spectinomycin (Trobicin $2 \mathrm{~g}$, Upjohn), and those with persistent chlamydial infection or postgonococcal urethritis received SMX-TMP two tablets by mouth twice daily for two days, erythromycin stearate
(Abbotticin, Abbott), or a tetracycline in the usual dosages for seven days.

\section{Statistical analysis}

Fisher's exact probability test was used for verification of treatment results.

\section{Results}

Of the 201 men treated on the basis of the entry criteria, 23 did not return for subsequent examination and were therefore excluded from the analysis. Among the remaining 178 patients, gonorrhoea was proved by culture in 162,42 of whom had a simultaneous infection with $C$ trachomatis.

Table I shows culture results and the allocation of patients to each treatment group. Three of the 85 patients in group A and 11 of the 77 in group B $(p<0.05)$ were still infected with gonococci after treatment. Among those with persistent $N$ gonorrhoeae in group A two men were infected with $\beta$-lactamase producing strains, two admitted re-exposure, and seven cases could be ascribed to treatment failure. In group B all three treatment failures were due to resistant strains.

TABLE I Results of cultures for $N$ gonorrhoeae and $C$ trachomatis before treatment and assignment of patients two treatment groups.

\begin{tabular}{|c|c|c|c|}
\hline \multirow[b]{2}{*}{ Positive cultures for: } & \multicolumn{3}{|c|}{ Patients treated with } \\
\hline & $\begin{array}{l}\text { Ampicillin- } \\
\text { probenecid } \\
\text { (group } A)\end{array}$ & $\begin{array}{l}\text { Sulphamethoxazole- } \\
\text { trimethoprim } \\
\text { (group B) }\end{array}$ & Total \\
\hline $\begin{array}{l}N \text { gonorrhoeae } \\
\text { Both organisms }\end{array}$ & $\begin{array}{l}77 \\
17\end{array}$ & $\begin{array}{l}85 \\
25\end{array}$ & $\begin{array}{r}162 \\
42\end{array}$ \\
\hline
\end{tabular}

Table II shows the effect of treatment on $C$ trachomatis infection. Before treatment 42 of $162(26 \%)$ patients with positive gonococcal isolates had coexistent $C$ trachomatis infection, of whom 17 were in group $A$ and 25 in group B.

TABLE II Eradication of $C$ trachomatis in men with gonococcal urethritis (percentage cure rates in parentheses).

\begin{tabular}{lll}
\hline & \multicolumn{2}{l}{ Patients treated with: } \\
\cline { 2 - 3 } $\begin{array}{l}\text { Positive cultures } \\
\text { for C trachomatis: }\end{array}$ & $\begin{array}{l}\text { Ampicillin- } \\
\text { probenecid } \\
\text { (group } A \text { ) }\end{array}$ & $\begin{array}{l}\text { Sulphamethoxazole- } \\
\text { trimethoprim } \\
\text { (group B) }\end{array}$ \\
\hline $\begin{array}{l}\text { Before treatment } \\
\text { After treatment }\end{array}$ & $17 / 77$ & $25 / 85$ \\
$\begin{array}{l}\text { Second visit } \\
\text { Third visit }\end{array}$ & $28 * / 77(0)$ & $4+/ 85(84)$ \\
& $18 \neq / 52(0)$ & $8 / 61 \quad(68)$ \\
\hline
\end{tabular}

* 3 probable reinfections, and 11 newly culture positive patients; †1 probable reinfection; $\$ 1$ newly culture positive patient. 
After treatment, $C$ trachomatis was reisolated from 17 men in group $A$ and 11 additional patients became culture positive. In group B, $C$ trachomatis was reisolated from 4 of 25 men initially giving positive results for chlamydia, although one of them had had sexual contact in the interim. At the last visit $C$ trachomatis was isolated from 8 of $61(13 \cdot 1 \%)$ men in group B. Three of these patients had persistent infection (positive results at all three visits.

\section{POSTGONOCOCCAL URETHRITIS}

In group $A$ there were 11 patients with persistent gonococcal infection, all of whom had five or more polymorphonuclear leucocytes per high power field. Of the remaining $66,30(45 \%)$ men cured of gonorrhoea had postgonococcal urethritis, and $C$ trachomatis was isolated from $26(86 \cdot 6 \%)$ of them. Remarkably, $C$ trachomatis was also isolated from two men without urethral leucocytosis.

In group B three patients had persistent gonococcal infection with five or more polymorphonuclear leucocytes per high power field. Eight of the 82 $(\mathbf{9} \cdot \mathbf{8 \%})$ men cured of gonococcal urethritis had postgonococcal urethritis, and $C$ trachomatis was isolated from three $(37 \cdot 5 \%)$ of them. Chlamydia was also isolated from one patient without postgonococcal urethritis. There was a significant $(p<0.001)$ difference in the rate of postgonococcal urethritis between group $\mathbf{A}$ and group $\mathbf{B}$.

\section{SIDE EFFECTS}

In group A four patients had diarrhoea; one of them complained of moderate nausea and severe headache. In group B six patients experienced side effects, of whom two had mild diarrhoea, two complained of moderate nausea, and two had skin reactions, one of whom complained of itching and the other had a rash on both legs.

\section{Discussion}

This study shows that SMX-TMP in a dose of four tablets twice daily for two days was more effective than a single dose of $2 \mathrm{~g}$ ampicillin plus $1 \mathrm{~g}$ probenecid in the treatment of gonorrhoea in men $(p<0.05)$. Eleven of $87(12 \cdot 6 \%)$ patients had persistent infection after ampicillin treatment, which is a high failure rate. When it was first introduced in Norway in 1967, the combination of $2 \mathrm{~g}$ ampicillin and $1 \mathrm{~g}$ probenecid gave only a $1 \cdot 2 \%$ failure rate. ${ }^{16}$ The increasing frequency of isolating penicillin resistant gonococci confirms observations from other countries.

In this study 42 of $162(25.9 \%)$ men had concomitant infection with $C$ trachomatis. This finding is in keeping with previous studies..$^{1-5}$ As in earlier observations, ${ }^{1} 5$ ampicillin failed to eradicate $C$ trachomatis, which was isolated from 28 of 77
$(36.4 \%)$ men after treatment. The effect of repeated specimen collection on the rate of isolation can be explained by the fact that $C$ trachomatis has a longer incubation time than gonococci. It may also be easier to obtain epithelial cells in the absence of gonococcal discharge. ${ }^{125}$

This study confirms others in which very high cure rates $(96-99 \%)$ were described when using SMXTMP twice daily for two days to treat gonococcal urethritis in men. ${ }^{6-9}$ The same regimen seemed to be somewhat less effective in women ( $9 \%$ failure rate), but male partners had not been treated in these cases. 12

Brunham et al isolated $C$ trachomatis from only one of 10 patients treated with SMX-TMP, two tablets twice daily for two days, compared with 10 of 11 women treated with ampicillin. ${ }^{12}$ In this study postgonococcal urethritis was usually associated with $C$ trachomatis. Of the $\mathbf{3 0}$ men with five or more polymorphonuclear leucocytes per high power field in group A, 26 gave positive results for chlamydia after treatment.

Patients with urethral leucocytosis from whom neither gonococci nor $C$ trachomatis could be isolated were equally distributed between the two treatment groups, with four such patients in group A and five in group B. None of these nine patients returned for more than one follow up visit. This suggests that postgonococcal urethritis not caused by chlamydia is more likely to be self limiting and may resolve spontaneously without further treatment.

In this study single dose treatment with ampicillin and probenecid was ineffective against $C$ trachomatis in simultaneous infection with $N$ gonorrhoeae. Sulphamethoxazole-trimethoprim treatment of acute, uncomplicated gonococcal urethritis in men gave a cure rate which was comparable with that in earlier studies carried out in Norway and other countries. SMX-TMP was effective in double infection with $N$ gonorrhoeae and $C$ trachomatis. Treatment of acute gonococcal urethritis with SMXTMP could be particularly advantageous in younger age groups where double infections with $N$ gonorrhoeae and $C$ trachomatis are especially frequent.

We thank our clinical colleagues Drs Audun Gautestad, Magn-Bjørn Hornnes, Bjørnar Johansen, Rein Knoph, Gunnar Mouland, Øyvind Sørensen, and Finn-Tysland Johnsen for providing specimens and data from their patients, and Berit Sandstad, MSc for statistical consultation.

\section{References}

1. Oriel JD, Ridgway GL. Genital infection by Chlamydia trachomatis: current topics in infection (series 2), London: Edward Arnold, 1982. 
2. Taylor-Robinson D, Thomas BJ. The role of Chlamydia trachomatis in genital tract and associated diseases. J Clin Pathol 1980; 33:205-33

3. Schachter J, Caldwell HD. Chlamydiae. In: Starr MP, Ingraham JR, Balows A, eds. Annual review of microbiology. Palo Alto: Annual Reviews Inc 1980; 34:285-309.

4. Oriel JD, Reeve P, Thomas BJ, Nicol CS. Infection with Chlamydia group A in men with urethritis due to Neisseria gonorrhoeae. J Infect Dis 1975;131: 376-82.

5. Oriel JD, Ridgway GL, Reeve P, Beckingham DC, Owen J. The lack of effect of ampicillin plus probenecid given for genital infections with Neisseria gonorrhoeae on associated infections with Chlamydia trachomatis. J Infect Dis 1976; 133:568-71.

6. Arya OP, Pearson CH, Rao SK, Blowers R. Treatment of gonorrhoea with trimethoprim-sulphamethoxazole in Uganda. Br J Vener Dis 1970; 46:214-6.

7. Mahony JDH, McCann JS, Harris JRW. Comparison of trimethoprim-sulfamethoxazole and penicillin in the treatment of gonorrhea. J Infect Dis 1973;49:517-20.

8. Austin TW, Brooks GF, Bethel M, Roberts FL, Turck M, Holmes KK. Trimethoprim-sulfamethoxazole in the treatment of gonococcal urethritis: clinical and laboratory correlates. $J$ Infect Dis 1973; 128suppl: 666-72.

9. Svindland HB. Treatment of gonorrhoea with sulphamethoxazole-trimethoprim: lack of effect on concomitant syphilis. Br J Vener Dis 1973; 49:50-3.

10. Sattler FR, Ruskin J. Therapy of gonorrhea. Comparison of trimethoprim-sulfamethoxazole and ampicillin. JAMA 1978; 240:2267-70.

11. Phillips I. Assessment of the role of co-trimoxazole in the treatment of gonorrhea. In: Brooks GF, Gotschlich EC, Holmes KK, Sawyer D, Young FE, eds. Immunobiology of Neisseria gonorrhoeae. Washington, DC: American Society for Microbiology, 1978; 86-8.
12. Brunham RC, Kuo C-C, Stevens CE, Holmes KK. Treatment of concomitant Neisseria gonorrhoeae and Chlamydia trachomatis infections in women: comparison of trimethoprimsulfamethoxazole with ampicillin probenecid. Rev Infect Dis 1982; 4:491-4.

13. Jaffe HW, Biddle JW, Johnson SR, Wiesner PJ. Infections due to penicillinase-producing Neisseria gonorrhoeae in the United States: 1976-80. J Infect Dis 1981;144:191-7.

14. Johannisson G, Sernryd A, Lycke E. Susceptibility of Chlamydia trachomatis to antibiotics in vitro and in vivo. Sex Transm Dis 1979;6:50-7.

15. Hammerschlag M. Activity of trimethoprim-sulfamethoxazole against Chlamydia trachomatis in vitro. Rev Infect Dis 1982; 4:500-5.

16. Gundersen $T, \emptyset$ degaard $K$, Gjessing $H$. Treatment of gonorrhoea by one oral dose of ampicillin and probenecid combined. Br J Vener Dis 1969; 45:235-7.

17. Ødegaard $K$, Solberg $O$, Lind J, Myhre G, Nyland B. Lincomycin in selective medium for the isolation of Neisseria gonorrhoeae. Acta Pathol Microbiol Scand [B] 1975; 83:301-4.

18. Csángó PA. Chlamydia trachomatis from men with nongonococcal urethritis. Simplified procedure for cultivation and isolation in replicating McCoy cell culture. Acta Pathol Microbiol Scand [B] 1978;86:257-9.

19. Ripa KT. Mårdh P-A. Cultivation of Chlamydia trachomatis in cycloheximide treated McCoy cells. J Clin Microbiol 1977; 6:328-31.

20. Ripa KT, Svensson L, Mårdh P-A, Westrơm L. Chlamydia trachomatis cervicitis in gynecologic outpatients. Obstet Gynecol 1978;52:698-702. 